\section{Polish censorship}

Copies of the Polish censorship regulations and instructions for the period February 1974-February 1977 have recently become available, via the unofficial "Social Self-Defence Committee" (formerly the "Workers' Defence Committee").

The subjects of banned articles during this period included: reports on industrial pollution of the environment, criticism of the bill on psychiatric medicine, information on the carcinogenic properties of PVC, discussion of the backwardness of scientific education in comparison with the West, errors in the selection of candidates for higher education, and data on the type of parasites afflicting Polish cattle.

The standing "Notes and Recommendations of the Central Office of Control of the Press, Publications and Entertainment" specifically prohibited publication of information on chemical hazards in industry and agriculture, work safety and hygiene, alcoholism, the Katowice mine disaster, and the purchase by Poland of production licences from capitalist countries.

Vera Rich

\section{US soldiers in cancer study}

THE US Department of Defense has promised to undertake a "crash programme" to examine the records of military personnel exposed to nuclear weapons tests in the $1950 \mathrm{~s}$ to see if they provide evidence of any abnormal incidence of cancer. The promise was made by the deputy director of the Defense Nuclear Agency, to a House sub-committee on health and the environment during the course of public hearings last week on the dangers of low level radiation.

The sub-committee has been particularly concerned at evidence suggesting an abnormally high incidence of leukaemia among the 2,235 soldiers who took part in manoeuvres after a 45-kiloton test shot, known as Smokey, which was detonated in the Nevada desert in 1957.

A study of the possible carcinogenic effects of radiation on those involved is being carried out by the Center for Disease Control, whose director, Dr William $\mathrm{H}$. Foege, told the sub-committee that the eight reported cases of leukaemia among the 2,235 was "out of the normal range".

Earlier Dr Karl Z. Morgan, who at the time of the test shot was director of health physics at the Atomic Energy Commission's Oak Ridge Laboratory, told the committee that his staff had been unable to retrieve scientific measuring equipment after the shot because of "residual contamination". He had "no doubt whatever" that this radiation had caused the leukaemia now found in those who had taken part in the manoeuvres.

Dr Morgan, who is now a professor at the school of nuclear engineering of the Georgia Institute of Technology, criticised scientists who refused to accept evidence that there is no safe level of radiation, and that any dose, however small, can cause leukaemia and other forms of cancer.

"One of the many problems we face today is that many scientists have accepted the threshold hypothesis as a cardinal law and have lived with this hypothesis so long that they have become staid or petrified in their thinking. Now they cannot believe or accept the fact that the threshold hypothesis is wrong", Dr Morgan said.

David Dickson

\section{Brothers in human rights \\ test case}

THE cyberneticist Gol'dshtein brothers -Grigorii and Isai-of Tbilisi, first hit the "human rights" headlines in 1975, when their exclusion from the Tbilisi Conference on Artificial Intelligence led to a confrontation between the international conference committee, who urged their admission, and the Georgian 'hosts'. The brothers are now, once again, involved in what may prove to be a test case-Grigorii has been arrested, and Isai has been threatened with arrest on the charge of parasitism and "malicious evasion of socially useful work".

The charge of "parasitism" (being without visible means of support) was brought last year against refusnik Iosif Begun, who was sentenced to two years exile in Siberia. The authorities refused to acknowledge that he had

\section{New threat to helium reserves}

A demand that "all appropriate measures" be taken to conserve rapidly-diminishing supplies of helium for potential future use has been made in a report published last week by a committee of the US National Academy of Sciences. The committee, which was set up last autumn to provide the administration with independent advice on the politically-sensitive issue of helium conservation, suggests that there is "a strong case for building a substantial government-owned strategic reserve of helium". It also condemns the present venting of separated helium into the atmosphere by natural gas-producers. any means of livelihood, since his current occupation-teaching Hebrew - was not a recognised profession. The Gol'dshtein bothers, however, until their dismissal from the Mendeleev Institute of Metrology in 1971, had been earning 600 roubles $(£ 300$ ) per month each. Since the minimum wage in the Soviet Union is 60 roubles per month, the Gol'dshteins have managed to convince the authorities that they have been living on savings lawfully laid by from their earnings. Nevertheless, it is claimed, they are evading their responsibilities by failing to undertake socially useful work.

Both brothers were dismissed from their Institute in the routine manner, following their application for an emigration visa - an application which was refused on the familiar grounds of access to secret information. Unlike most refusniks, they have now been "offered" jobs commensurate with their academic status, Grigorii in October 1977 and Isai in January 1978. These jobs, however, are at the "closed" Institute of Explosives Research in Tbilisi, where all work is potentially secret, and both in turn have refused to accept the offers.

On 17 January, Grigorii was arrested, and was released ten days later on a written undertaking not to leave Tbilisi. His trial is expected "perhaps in two to three weeks". On 19 January, Isai received an ultimatum from the police, that unless he finds a job within a month, he too will be arrested.

The Gol'dshtein brothers are so adamant in their desire to emigrate to Israel that in 1972 they unilaterally renounced their Soviet citizenship. Clearly, they are hardly the loyal comrades one would expect to find working in a secret institution. The jobs proposed for them are, they feel, yet another means of preventing their emigration.

Vera Rich

Most scientists know helium merely as the second lightest element. Some have used its properties as a gas to fill meteorological balloons; others have tnore recently exploited its superconducting properties at temperatures close to absolute zero-where it remains in liquid form-for experiments ranging from nuclear fusion to the superconducting magnets that will be used in Fermilab's new energy saver/doubler.

But although current applications remain relatively limited, helium has become a major headache for the US government. Reserves of helium-rich natural gas, from which helium can 
be extracted many times more cheaply than from air, are known to be very limited and, at current extraction rates, rapidly diminishing.

Awareness of a potential shortage of helium dates back to 1960 when the administration, with one eye on future federal needs for both defence and space research projects, passed a Helium Act. Under the terms of the act four companies were contracted to separate helium for storage from natural gas; the conserved helium was stored in the partially depleted Cliffside natural gas field near Amarillo in Texas, which at present contains about 39 billion cubic feet (bcf) of the gas.

But the act turned out to be an embarrassing and expensive mistake. With the run-down in both defence research and the space programme at the end of the $1960 \mathrm{~s}$, demand for helium dropped dramatically below expected levels-by 1971 the total market demand for helium was only half what had been predicted-with no indications that the situation would improve in the near future. The government's problems were compounded by the fact that private suppliers were able to offer helium at much lower prices than the administration.

The net result was that sales of helium by the Bureau of Mines in 1971 were lower by a factor of six than had been predicted. And the massive federal investment in conservation measures had resulted in an annual bill in interest charges alone of over \$20 million, with sales averaging only about $\$ 1$ million. One reaction was the immediate termination of the contracts with the four private suppliers-action which has resulted in lengthy litigation still making its way through the courts. Since then, natural gas producers have been venting helium either directly or indirectly into the atmosphere. And there have been growing demands from Congress that the whole issue of helium conservation should be looked at more closely, with an eye to new legislation replacing the 1960 act.

Last September the appropriation committees of both the Senate and the House ordered that a study of the present situation, with recommendations about possible new legislation, be carried out jointly by the Department of the Interior's Bureau of Mines and the Department of Energy (then the Energy Research and Development Administration). In their turn, these two agencies, which had also brought in the Department of Defense and the National Aeronautics and Space Administration (NASA) as two of the largest helium-users, decided that an assessment of the situation should be obtained from an independent non-

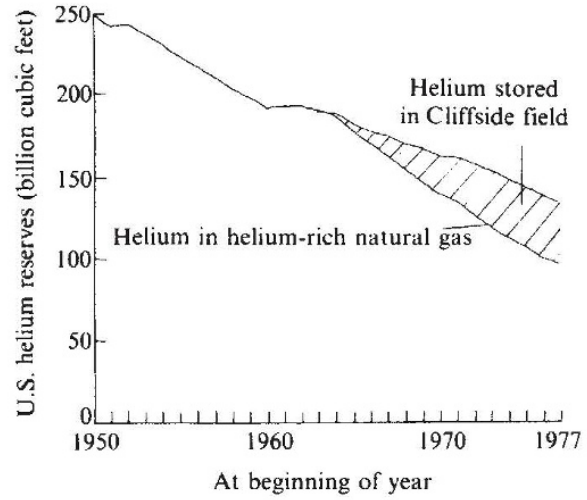

which commissioned it, they are likely to put a more subdued case in their own report to Congress, which is expected to be delivered within the next few weeks. Administration officials agree, for example, on the need to stimulate private industry's interest in helium conservation-but they feel that by concentrating on the the situation of supplies of helium-rich gas, insufficient attention has been given to the potential for extracting helium from ordinary natural gas.

Furthermore there is a feeling that the NAS report may have been too optimistic in its predictions of future demand for helium. For example, the report quotes a prediction by the Argonne National Laboratory that by the year 2050 the annual requirement for helium from fusion reactors and superconducting energy storage alone will be between 10.4 and 15.4 bcf. In contrast, information gathered from government agencies indicate that consumption in 2030 will probably be between 3 and 8 bcf.

The agencies, which have been asked by Congress for advice as to possible government action and future legislation, are therefore unlikely to recommend the renewed stockpiling of helium, at least not in the near future. Dr Ray Munnerlyn, who is responsible for helium policy at the Department of the Interior, said last week that in the present circumstances, he would personally be opposed to a recommendation that Congress should renew its helium purchases.

David Dickson Furthermore although current annual demand is only about 1 bcf, this figure is likely to be considerably higher by the middle of the next century, with potential applications in fields such as fusion and gas nuclear reactors, laser-based missile defence systems, and advanced energy conversion cycle.

"It is clear that even the maximum possible helium conservation programme will only buy time in which to adjust to the extraction of helium from air as the sole source" the committee says. It agrees that as a result of earlier conservation policies there is at present enough helium stored to meet federal requirements into the next century, but writes that "the case for helium conservation is long-term based on the interest of future generations ..."

The report also points out that there is, at present, little market incentive for conservation of helium by private producers. It therefore suggests that the government contemplate taking "an aggressive role to resolve the legal and market uncertainties currently discouraging helium conservation."

Although the conclusions of the NAS report coincide broadly with the views of the government agencies

\section{Erratum}

We would like to apologise for the errors which slipped into the article 'Dioxin meeting recommends cancer study' on page 202 of 19 January issue. They resulted from dictation over the phone and subsequent editing and are amended as follows. The first sentence of the first paragraph should have begun: "Since the release of the tetrachlorinated dibenzo-p-dioxin (the isomer 2,3,7,8 tetrachlorodibenzo-p-dioxin) . . ." The company referred to as the Doll Chemical Company is in fact the Dow Chemical Company and $\mathrm{Dr}$ Rodolfo Saracci is at the Unit of Epidemiology and Biostatistics, not Immunology and Biostatistics as reported. The two groups from the University of Wisconsin and the Dow Chemical Company, which the article claimed reported animal studies to test the carcinogenicity of dioxin, were not in fact present at the meeting; their work was discussed in their absence. 